\title{
8
}
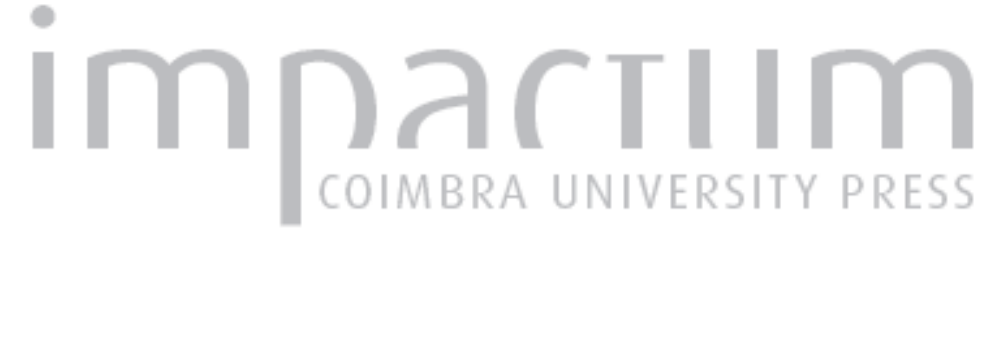

\section{A importância da analise dos riscos de contaminação na reabilitação de brownfields urbanos}

Autor(es): $\quad$ Lombardo, Magda Adelaide; Volpe, Larissa Lucciane; Vasques, Amanda

Publicado por: Associação Portuguesa de Riscos, Prevenção e Segurança

URL

persistente:

URI:http://hdl.handle.net/10316.2/36015

DOI:

DOI:http://dx.doi.org/10.14195/1647-7723_19_19

Accessed : $\quad$ 26-Apr-2023 14:24:48

A navegação consulta e descarregamento dos títulos inseridos nas Bibliotecas Digitais UC Digitalis, UC Pombalina e UC Impactum, pressupõem a aceitação plena e sem reservas dos Termos e Condições de Uso destas Bibliotecas Digitais, disponíveis em https://digitalis.uc.pt/pt-pt/termos.

Conforme exposto nos referidos Termos e Condições de Uso, o descarregamento de títulos de acesso restrito requer uma licença válida de autorização devendo o utilizador aceder ao(s) documento(s) a partir de um endereço de IP da instituição detentora da supramencionada licença.

Ao utilizador é apenas permitido o descarregamento para uso pessoal, pelo que o emprego do(s) título(s) descarregado(s) para outro fim, designadamente comercial, carece de autorização do respetivo autor ou editor da obra.

Na medida em que todas as obras da UC Digitalis se encontram protegidas pelo Código do Direito de Autor e Direitos Conexos e demais legislação aplicável, toda a cópia, parcial ou total, deste documento, nos casos em que é legalmente admitida, deverá conter ou fazer-se acompanhar por este aviso. 


\section{territorium}

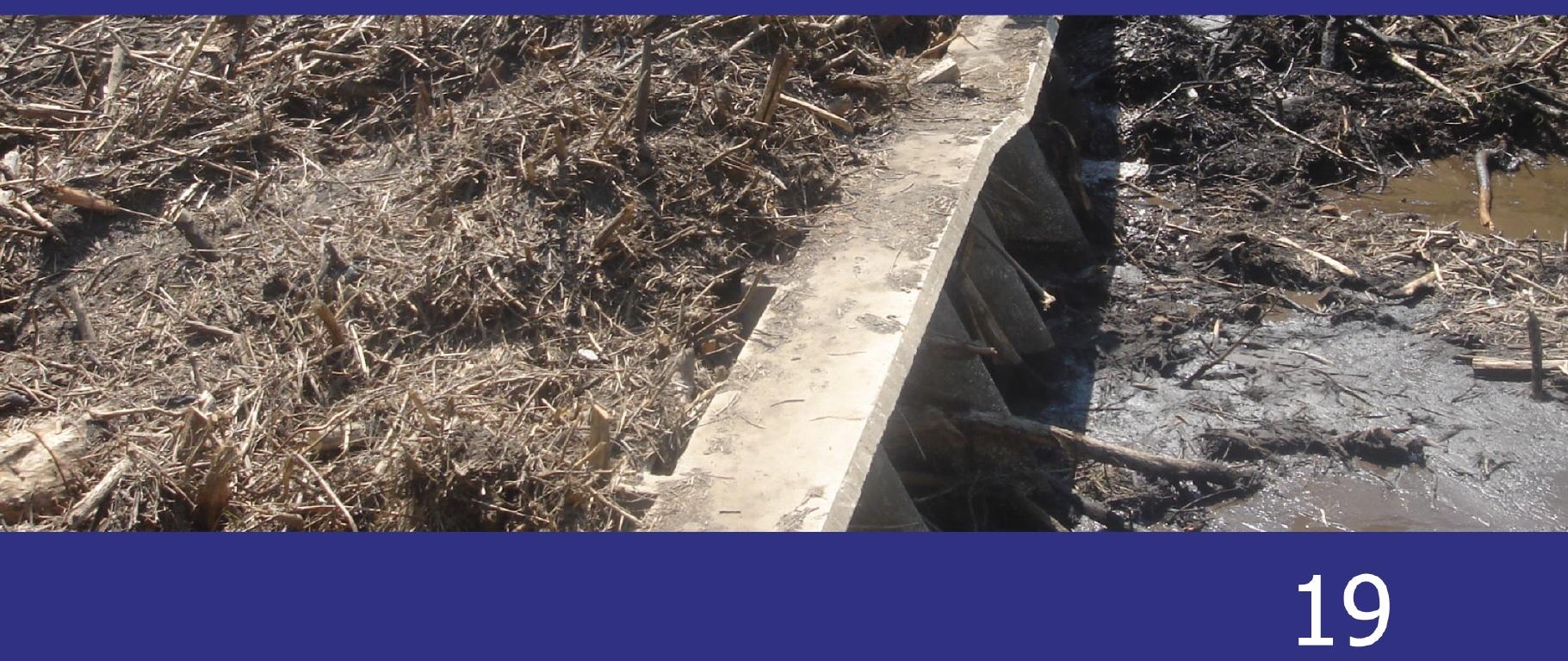

\section{Reequacionar o Conhecimento dos Riscos e das Catástrofes}

Revista da Associação Portuguesa de Riscos, Prevenção e Segurança 
Centro de Análise e Planejamento Ambiental, Instituto de Geociências e Ciências Exatas da Universidade Estadual Paulista - UNESP, Brasil

lombardo@rc.unesp.br

Larissa Lucciane Volpe

Instituto de Geociências e

Ciências Exatas da Universidade Estadual Paulista - UNESP, Brasil

lvgeo@rc.unesp.br

Amanda Ramalho Vasques

Universidade de São Paulo, Brasil amandav@usp.br

\section{RESUMO}

Esta pesquisa objetivou analisar os riscos de contaminação em locais brownfields, uma vez que muitas indústrias desenvolveram atividades potencialmente contaminadoras, tornando os imóveis e terrenos impróprios ou restritos para um novo uso. Foram analisadas propostas de reabilitação e diretrizes para nortear planos de reocupação do imóvel, fazendo-se necessário o estudo das legislações ambientais que determinam a qualidade dos solos e os riscos a serem minimizados no processo de reabilitação, que está intimamente relacionado aos riscos de saúde pública que uma área contaminada pode trazer para a comunidade vizinha a estes locais.

Palavras chave: Brownfields, riscos, contaminação, reabilitação.

\section{RESUMEN}

La importancia del análisis de riesgos de contaminación urbana en la rehabilitation de los brownfields - Este estudio analiza los riesgos de contaminación en los sitios de terrenos industriales abandonados (brownfields), una vez que muchas industrias han desarrollado actividades potencialmente contaminantes, restringidos a un nuevo uso de los bienes inmuebles y terrenos. Se analizaron propuestas para la rehabilitación y directrices para orientar los planes de volver a ocupar la propiedad, lo que requiere el estudio de las leyes ambientales que determinan la calidad del suelo y reducir al mínimo los riesgos en el proceso de rehabilitación, que se relaciona con riesgos para la salud pública que un área contaminada puede aportar a la comunidad que rodea a estos sitios.

Palabras clave: Brownfields, riesgos, contaminación, rehabilitación.

\section{RÉSUMÉ}

L'importance de l'analyse des risques de contamination een milieuurbain dans la réhabilitation de brownfields - Cet article analyse les risques de contamination sur les sites de friches industrielles, parce que nombreuses industries ont développé des activités potentiellement contaminantes, ce qui rend l'immobilier et les terres impropres à une nouvelle utilisation. Nous avons analysé les propositions de réhabilitation et les lignes directrices pour orienter les plans de réoccuper la propriété, ce qui a besoin de l'étude des lois sur l'environnement qui déterminent la qualité des sols. Les risques doivent être réduits au minimum dans le processus de réadaptation, qui est étroitement lié aux risques de santé publique qu' une zone contaminée peut apporter à la communauté environnante de ces sites.

Mots-clés: Friches industrielles, risques, contamination, réhabilitation.

\section{ABSTRACT}

The importance of risk analysis of urban contamination in the rehabilitation of the brownfields - This research had the goal to analyze the risks of contamination in brownfields sites, since many industries developed activities with potential contamination, making the real state and terrains unfit or restricted to a new use. Proposals were analyzed for rehabilitation and guidelines to regulate plans for real state reoccupation, becoming necessary the study of environmental legislation to define the soil quality and risks to be minimized in the rehabilitation process that is closely related to the risks to public health that a contaminated area may bring to the surrounding community of these sites.

Key words: Brownfields, risks, contamination, rehabilitation.

* O texto deste artigo corresponde à comunicação apresentada ao II Congresso Internacional de Riscos e VI Encontro Nacional, tendo sido submetido para revisão em 23-04-2010, tendo sido aceite para publicação em 13-08-2010.

Este artigo é parte integrante da Revista Territorium, n. ${ }^{\circ} 19,2012,{ }^{\circ}$ RIscos, ISBN: 0872- 8941. 


\section{Introdução}

Segundo SÁnchez (2001), todos os empreendimentos têm uma vida útil ou um ciclo de vida. Devido a razões econômicas, ambientais, de mercado, atraso tecnológico, e muitas outras, as indústrias fecham, as minas são abandonadas, os depósitos esgotam sua capacidade de estoque, muitas estações e trilhos ficam ociosos, os portos ficam pequenos demais para comportar grandes navios, as barragens são desativadas, ou seja, tornam-se finitas as suas funções.

Uma vez que se desativa um empreendimento, é preciso ter em conta que o fechamento de uma fábrica ou o encerramento de qualquer uma das atividades acima não é isento de consequências negativas do pósencerramento, principalmente porque muitas atividades não têm um plano preventivo - um planejamento da desativação do empreendimento. Quando a reparação de danos ambientais incrementou o cálculo do valor de uma empresa a ser vendida, o conceito de passivo ambiental ganhou notoriedade. Ele é definido como: o acúmulo de danos ambientais que devem ser reparados a fim de que seja mantida a qualidade ambiental de um determinado local. O termo passivo ambiental é empregado com freqüência no sentido monetário, para conotar o acúmulo de danos infligidos ao meio natural por uma determinada atividade ou pelo conjunto de ações humanas, danos esses que muitas vezes não podem ser avaliados economicamente. Representa, num sentido figurado, uma 'dívida' para com as gerações futuras (Sánchez, 2001, p.18,19). Além do problema ambiental herdado, existe um passivo financeiro (Ś́nchez 2001, p.94) que não pode ser descartado: salários, direitos trabalhistas, dívidas junto a credores, etc. Existe também um passivo social - o desemprego, doenças respiratórias por poluição do ar, enfermidades pela presença de poluentes na água e no solo, atividades com alto índice de acidentes de trabalho e outros. Finalmente, existe ainda um passivo espacial - as áreas abandonadas que se degradam no decorrer dos anos - os locais brownfields.

A contaminação por antigas atividades industriais é uma forma muito comum de impacto ambiental. O número de áreas contaminadas é mais alto principalmente em países que tiveram um crescimento industrial desvinculado de planejamento. Conhecer a atividade industrial pretérita e analisar vestígios de contaminação no local é uma etapa muito importante no processo de reabilitação. Medidas corretivas são adotadas em vários países que consideram o assunto de extrema importância para a proteção da saúde da população e qualidade ambiental.

A identificação das áreas para possível recuperação já é um processo freqüente nos Estados Unidos e em países europeus. Para tanto, deve-se realizar um estudo minucioso referente a situação das estruturas das edificações, bem como dos solos em que estão inseridas.

Algumas cidades como Pittsburg (EUA), com o auxílio da Agência Nacional de Proteção Ambiental (EPA), conseguiu reutilizar os espaços abandonados pela indústria do aço, gerando emprego para população e aproveitando a infra-estrutura local.

No Brasil, muitas cidades de passado fabril apresentam extensas áreas em estado de abandono derivadas de antigas atividades indústriais e seus galpões. 0 assunto ainda está sendo discutido nos estados e municípios brasileiros para elaboração de projetos de leis sobre reutilização de espaços obsoletos e suspeitos de contaminação, com o objetivo de readequá-los às necessidades da população, considerando principalmente seu entorno e enquadrando a nova função do imóvel ao cenário urbano existente.

\section{Análise de riscos de contaminação em locais brownfields}

Muitas indústrias manipulam ou manipularam no passado, substâncias químicas tóxicas durante o período de atividades, podendo ter armazenado resíduos contaminantes em contato direto com o solo ou despejado direto em rios. Nestes casos, estas áreas podem ser suspeitas de contaminação, assim o seu manejo e a eliminação dos riscos ambientais de acordo com o uso da área é o objetivo principal do gerenciamento do solo contaminado (GRIMSKI, 2004, p.3).

Segundo CUNHA (1997, p.1) as áreas contaminadas podem ser definidas como locais que apresentam a presença de substâncias tóxicas distribuídas de forma não controlada nos diferentes compartimentos do ambiente, as quais, em função do nível de concentração existente, determinam riscos potenciais à saúde dos seres vivos ou prejuízos à qualidade dos recursos naturais. Muitas vezes, a população do entorno destas áreas desconhecem possíveis riscos trazidos pela contaminação, conhecendo apenas o impacto social no local.

De acordo com LAGE (2003, p.33,34), o passivo ambiental pode ser avaliado em cinco etapas

-Etapa I - Revisão Histórica: a fábrica, depósito, galpão, terreno, etc. são avaliados em relação ao seu uso passado. Nesta etapa, pessoas são entrevistadas, documentos são analisados e o local é inspecionado.

-Etapa II - Levantamento Detalhado de Dados: em função dos resultados obtidos na etapa anterior, iniciam-se estudos mais detalhados, como por exemplo, a realização de uma avaliação hidrogeológica, onde se analisam compostos orgânicos no solo e no lençol freático. 
-Etapa III - Padrão de referência: a questão que norteia a etapa III é "O quanto o limpo é limpo?". O padrão aceito de limpeza é obtido quando a situação deixada não irá causar mal algum para alguém, hoje e no futuro.

-Etapa IV - Escolha do Processo de Limpeza: uma vez que as etapas anteriores permitiram avaliar a presença e o nível de contaminação, e o nível final para que a propriedade seja considerada limpa, resta escolher o processo adequado para obter as concentrações desejadas.

-Etapa V - Remediação: colocar em prática o processo de limpeza com uso da tecnologia mais adequada, o que varia de caso para caso.

Estas etapas resumem algumas formas de se tratar áreas contaminadas por atividades pretéritas industriais. Geralmente haverá a necessidade de reconstituir a história do local, coletar as amostras de solos para verificar a existência de agentes contaminantes, escolher um método de limpeza que se mostre eficiente para o caso específico que está sendo tratado.

Segundo Russ (2000) "as condições ambientais e contaminantes específicos encontrados em áreas de passivos sócio-ambientais estão inseridos nas investigações das condições gerais do local." O autor afirma que o processo de avaliação destas áreas ocorre em fases: $\bullet 1^{\circ}$ Fase: Informações coletadas sobre o local; - $2^{\circ}$ Fase: Avaliação ambiental. A Fase I ocorre a partir do conhecimento sobre a propriedade em registros públicos ou investigações de condições específicas suspeitas. A Fase II é completamente dependente e baseada na Fase I. A avaliação só ocorre quando a Fase I indicar potencial para ou contaminação atual. Na Fase II, o trabalho é normalmente direcionado para uma pesquisa específica. Baseia-se em fatos como solos manchados, conhecimento ou suspeita de reservatórios de armazenamento no subsolo, área de armazenamento químico ou área suspeita de contaminação por qualquer motivo. A proposta de trabalho na Fase II é normalmente confirmar pesquisas realizadas na Fase I.

De acordo com Russ (2000) as ações corretivas estão focadas na administração de um local visando controlar e limitar riscos. Em cada caso, o plano de remediação tem um objetivo específico, sendo sempre realizado em função da proteção da saúde humana e do meio ambiente. As ações corretivas podem ser aplicadas sob três considerações: fonte de informações sobre o contaminante e a contaminação; mecanismos de transporte; receptores. Os métodos que visam remover ou tratar a fonte de contaminação interrompem ou cessam os mecanismos de transporte controlando a exposição humana aos riscos.

\section{Responsabilidade Ambiental}

Àreas intensamente industrializadas, onde as atividades fabris contaminaram o solo, abriram espaço para uma discussão sobre quem deve pagar a conta da despoluição. A legislação demorou a regulamentar as atividades poluidoras e mais recentemente se adquiriu o hábito da fiscalização. Indústrias que tiveram vários donos, fábricas que faliram com dívidas, e outros casos onde não se consegue encontrar os 'culpados' para os custos financeiros, tornaram-se pauta em vários países. Nos EUA, nas décadas de 1970 e 1980, a Legislação Federal passou a regular a limpeza dos locais industriais poluídos. Esta legislação estabeleceu - Superfund, onde estão listados os casos mais urgentes para limpeza de brownfields. Estes locais muito contaminados engrossam a Lista de Prioridades Nacionais -NPL (Russ, 2000,p.5-6). A lei decide o responsável pela limpeza, o que recai geralmente sobre proprietários atuais ou passados. De acordo com SÁnchez (2001, p.128), a aplicação do Superfund é retroativa e estabelece a responsabilidade objetiva, "independente da existência de culpa"

Ao exercer determinada atividade, um empreendedor assume todos os riscos dela decorrentes, inclusive os ambientais, não sendo necessário provar sua imperícia, imprudência ou negligência para conseguir, em processos legais, que o responsável pague pela reparação do dano ambiental. Entretanto, a lei também proveu meios pelos quais um proprietário pode se defender das reivindicações de responsabilidade. 0 mais comum é a Defesa do Proprietário Inocente, onde o dono do terreno contaminado faz uma investigação dos usos históricos e da condição do terreno antes da compra, a fim de demonstrar que o mesmo não tinha nenhum conhecimento da contaminação ambiental (Russ, 2001, p.9).

O princípio poluidor-pagador está enunciado no Tratado que institui a Comunidade Européia. Esta política ambiental da União Européia (UE) considera que, se o operador não tiver possibilidade financeira de custear as medidas de reparação na sua totalidade ou parcialmente, ou ainda, se não é possível identificar o poluidor responsável, os Estados-Membros velam, em qualquer caso, assumindo a responsabilidade e instituindo, por exemplo, mecanismos de financiamento como garantias financeiras, cauções e fundos coletivos. Em um outro caso, se existir mais que um responsável pelos danos, todos deverão suportar os custos associados à reparação, quer solidariamente, quer numa base proporcional. A lei define poluidor como sendo a pessoa física ou jurídica, de direito público ou privado, responsável, direta ou indiretamente, pela atividade causadora da degradação ambiental. 
Um dos primeiros problemas citados por Billet (1999, p. 235) diz respeito à ausência do dono de um brownfield, ou seja, formalmente não é possível identificar o responsável pelo abandono ou contaminação das instalações. O local nestas condições é considerado 'órfão'. Os sítios órfãos contaminados são definidos como uma área que tenha sido irregularmente utilizada para a disposição de resíduos perigosos, cujos responsáveis pela disposição não sejam identificáveis. Muitas vezes, são consideradas 'órfãos' devido a dificuldade em encontrar o responsável pelo empreendimento.

Quando é possível identificar o responsável pela contaminação, aplica-se o princípio poluidor-pagador, ou seja, são atribuídos ao poluidor os custos necessários ao combate à poluição, conforme a determinação do poder público, a fim de manter o meio ambiente em estado aceitável. O poluidor é obrigado a indenizar ou reparar os danos causados ao meio ambiente e a terceiros, afetados por sua atividade. Este princípio não visa encobrir a poluição, mas evitar que o dano ecológico fique sem reparação.

A 'regra' européia do 'poluidor-pagador' faz parte da legislação francesa (Guelton, 1999, p. 235 e é aplicada responsabilizando o último proprietário a arcar com os custos de descontaminação do local. No caso dos sítios 'órfãos', a responsabilidade de limpar tais áreas recai sobre a ADEME (Agence de l'environnement et de la maîtrise de l'energie- Agência do Meio Ambiente e de Controle de Energia).

Em casos de negociações de compra e venda de terrenos poluídos, tem-se notado que a regra 'poluidorpagador' tem sido substituída pela prática de 'usuáriopagador', que, segundo Guelton (1999,p.235-236), pode ser explicada pelo fato do preço da venda do terreno ter dois componentes: o preço do terreno propriamente dito e um preço a ser pago pela despoluição. A lei considera que o preço da despoluição concerne ao vendedor como um elemento do preço do terreno. o princípio do usuário-pagador estabelece que os recursos naturais devam estar sujeitos à aplicação de instrumentos econômicos para que o seu uso seja feito em prol da coletividade, afixando um valor econômico ao bem natural.

No Brasil, segundo SANTOS (2003,p.554), o princípio 'poluidor-pagador' está presente na Declaração do Rio sobre Meio Ambiente e Desenvolvimento de 1992, princípio 16, artigo $4^{\circ}$, na Lei 6.938/81 (Política Nacional do Meio Ambiente); e na Lei 9.433/97 (Lei das Águas) e artigo 225, \$3 ${ }^{\circ}$ Constituição Federal. Ao Conselho Nacional do Meio Ambiente (CONAMA), compete homologar acordos transformando penalidades pecuniárias em obrigações para executar medidas de interesse à proteção ambiental.
A Lei 997/76, que dispõe sobre o controle da poluição ambiental no Estado de São Paulo, considera poluição o lançamento ou a liberação, nas águas, no ar ou no solo, de toda e qualquer forma de matéria ou energia, com intensidade, em quantidade de concentração ou com características em desacordo com as que forem estabelecidas, e que tornem ou possam tornar as águas, o ar ou o solo impróprios, nocivos ou ofensivos à saúde e danosos ao meio ambiente. Assim, verificamos que os conceitos de poluição e contaminação são muito próximos, possibilitando que os tratemos como sinônimos nesta pesquisa. Também é necessário conceituar áreas degradadas: pode-se definir como uma área onde ocorrem processos de alteração das propriedades físicas e/ou químicas de um ou mais compartimentos do meio ambiente.

Com o estudo da Regulamentação da Lei Federal Alemã de Proteção do Solo e de Áreas Contaminadas (documento atualizado em 1999 pela (ETESB), o Governo do Estado de São Paulo iniciou a elaboração dos projetos de lei visando o gerenciamento de áreas contaminadas. Dessa forma, propõe à Assembléia Legislativa o Projeto de Lei de Proteção da Qualidade do Solo e Gerenciamento de Áreas Contaminadas.

Segundo Volpe (2006, p.23), a proposta é inédita na Legislação Brasileira que desde a década de 1980, principalmente após a elaboração da Agenda 21 (documento elaborado em conferência organizada pela ONU em 1992), trabalha na elaboração de Leis Estaduais e Federais visando o manejo dos resíduos e o papel da indústria na sociedade. O Anteprojeto de Lei, em seu Capítulo I (um), Parágrafo Único, dispõe: Para efeito desta lei considera-se área contaminada aquela área, terreno, local, instalação, edificação ou benfeitoria, abandonado ou em atividade, que contém quantidades ou concentrações de matéria em condições que causem ou possam causar danos à saúde humana, ao meio ambiente ou a outro bem a proteger. Considera-se área contaminada aquela edificação abandonada ou em atividade que contém matéria em condições que causem danos à saúde humana ou ao meio ambiente. No caso de remediação das áreas contaminadas, a proposta discutiu parâmetros de valores de referência de qualidade, prevenção e intervenção. As tabelas são encontradas em documentos públicos elaborados pela Companhia Ambiental do Estado de São Paulo (CETESB) que substitui as tabelas de valores do "Relatório de estabelecimento de valores orientadores para solos e água subterrânea no Estado de são Paulo" mais antigos. 0 relatório considera para estabelecimento de valores, o uso e a ocupação do solo e grau de exposição do ser humano.

Entre os instrumentos de implantação do sistema para gerenciamento de áreas contaminadas estão: cadastro 
de áreas contaminadas, informações à população, plano de desativação, fiscalização, plano diretor e legislação de uso e ocupação do solo, plano de remediação, incentivo fiscal, fundos financeiros, critérios de qualidade para solo e água subterrânea entre outros. Sobre prevenção e controle de remediação do solo, o documento dispõe sobre a atuação do SEAQUA (Sistema de Administração de Qualidade Ambiental) que terá como parâmetros para fiscalização os valores de referência de qualidade, prevenção e intervenção, estabelecidos pelo órgão ambiental estadual. 0 documento considera perigo para a população a contaminação das águas superficiais ou subterrâneas utilizadas para abastecimento público e dispõe sobre as devidas providências a serem tomadas pelo responsável, órgão ambiental ou poder público. Segundo a Lei 997/76, art 60, incluem-se entre as atribuições da CETESB, para controle e preservação do meio ambiente; programar e realizar coleta de amostras; exames de laboratórios e análise de resultados; necessários à avaliação da qualidade do referido meio.

No Projeto de Lei de Proteção da Qualidade do Solo e Gerenciamento de Áreas Contaminadas, as áreas serão consideradas contaminadas sob investigação quando houver constatação da presença de contaminantes e o órgão ambiental deverá informar a população sobre a contaminação, bem como solicitar devidas providências ao responsável. No que diz respeito às áreas abandonadas, as quais o órgão ambiental encontra dificuldade em responsabilizar o empreendedor (por motivo de falência da empresa, falecimento do proprietário entre outros), é importante ressaltar que o parágrafo único do artigo 24 da Seção 3 cita que "na impossibilidade de identificação ou localização do responsável legal pela área contaminada, deverá o órgão ambiental oficiar ao Cartório de Registro de Imóveis com vistas a que seja divulgada, conjuntamente com as demais informações referentes à matrícula do imóvel, o fato do mesmo estar contaminado".

De acordo com o Projeto de Lei que estabelece diretrizes nacionais para o gerenciamento de resíduos sólidos, elaborado em 2006, define resíduos como: "resultantes do processo de produção, transformação, utilização ou consumo em atividade humana, a cujo descarte se procede, se propõe proceder ou está obrigado a proceder". Define como geradores de resíduos sólidos: "pessoas físicas ou jurídicas, de direito público ou privado, responsáveis por empreendimentos que gerem resíduos sólidos por meio de seus produtos ou atividades". É instrumento da política nacional de resíduos sólidos "O Fundo Nacional de Descontaminação de sítios Órfãos (Capítulo IV - Art. 43)." O CONAMA (Lei 6.938/81) estabelece normas como: organizar e realizar o levantamento nacional dos sítios órfãos contaminados. No artigo 44, fica instituído o Fundo Nacional para a Descontaminação de Sítios Órfãos, vinculado ao órgão federal ambiental competente definido em regulamento, com o objetivo de promover a descontaminação de áreas contaminadas por resíduos perigosos na impossibilidade de identificação dos responsáveis pela contaminação.

Regulamentação da Lei Federal Alemã de Proteção ao Solo e Áreas Contaminadas

A Alemanha estabeleceu um sistema jurídicoadministrativo de proteção do solo nas esferas federal, estadual e municipal. A Lei Federal de Proteção do Solo de 1984 contém um item especial sobre Areas Contaminadas (AC) que inclui a intervenção para modificar a situação de contaminação. Muitos estados, como Hessen por exemplo, criam suas próprias leis de AC. A Legislação Alemã define como Áreas Suspeitas (AS) de contaminação: "terrenos de estabelecimentos/ instalações (industriais) desativados e áreas de uso comercial, nos quais foram manuseadas substâncias com risco ambiental." Define como área contaminada: "Áreas que podem causar poluição do solo ou outros riscos ao bem-estar público e individual."

Os aspectos centrais na questão de AC abordados na Lei de Proteção do Solo são:

- Obrigatoriedade de levantamento e cadastramento de áreas suspeitas de contaminação (AS) pelo órgão público responsável;

- Definição do responsável: causador ou seu sucessor, proprietário ou arrendatário, locatário;

- Elaboração de um plano de remediação pelo responsável pela contaminação;

- Obrigatoriedade do responsável pela contaminação de realizar a remediação;

-Obrigatoriedade de informação ao público;

- Obrigatoriedade de colaboração e acesso aos dados relevantes do responsável;

- Obrigatoriedade de monitoramento.

Além disso, a regulamentação estabelece diretrizes concretas, bem como orientações práticas em nível técnico e legal para todos os aspectos administrativos do gerenciamento de $\mathrm{AC}$ e da questão de proteção do solo.

A Regulamentação da Lei Federal Alemã de Proteção do Solo e de Áreas Contaminadas (RLFPS) é muito estudada no Brasil a fim de servir como base e discutir o Projeto de Lei referente às áreas contaminadas. A RLFPS considera áreas desativadas "instalações onde foram tratados, armazenados, manipulados resíduos sólidos ou áreas industriais onde materiais ambientalmente nocivos foram usados". São apresentados valores de referência para avaliação de áreas contaminadas baseados no critério "vias de absorção" e "uso do solo" como auxílio 
aos órgãos estaduais e municipais competentes. 0 documento parte do conceito de "indícios da existência de uma contaminação danosa”, como por exemplo, o manuseio e/ou a disposição inadequada de substâncias perigosas, atividade industrial e irregularidades no funcionamento. De acordo com a via de absorção e o uso do solo são apresentadas tabelas com valoresreferência de investigação e intervenção para determinadas substâncias químicas contaminantes com o objetivo de avaliar áreas suspeitas de contaminação para futura ocupação. No Estado de São Paulo, os valores de referência complementam o projeto de Lei Proteção da Qualidade do Solo e Gerenciamento de Áreas Contaminadas, orientando a política de prevenção e gerenciamento do solo. 0 documento foi elaborado e atualizado pela Cetesb em 2005.

\section{Gerenciamento de áreas contaminadas no Brasil}

A CETESB em parceria com a empresa Deutsche Gesellschaft für Technische Zusammenarbeit - GTZ pela Agência Brasileira de Cooperação, também foi responsável pelo "Manual de Gerenciamento de Áreas Contaminadas" que visa o gerenciamento ambiental em áreas degradadas pela contaminação do solo e da água com base na Legislação Ambiental Alemã. 0 manual o gerenciamento de áreas contaminadas (ACs) visa diminuir os riscos a que estão sujeitos a população e o meio ambiente por meio de um conjunto de medidas que assegurem o conhecimento das características destas áreas e dos impactos causados. 0 gerenciamento de ACs baseia-se em uma estratégia constituída por etapas seqüenciais, em que a informação obtida em cada etapa é base para a execução da etapa posterior. 0 gerenciamento constitui-se do processo de identificação e processo de recuperação.

0 processo de identificação constitui-se de 4 etapas:

- Definição da região de interesse;

-Identificação de áreas potencialmente contaminadas;

-Avaliação preliminar;

-Investigação confirmatória.

O processo de recuperação de áreas contaminadas tem como objetivo principal a adoção de medidas corretivas que possibilite a recuperação da área para uso compatível após intervenção. 0 processo é constituído de 6 etapas:

- Investigação detalhada;

-Avaliação de risco;

- Investigação para remediação;

-Projeto para remediação;

-Remediação;

-Monitoramento.
No processo de identificação, a classificação ocorre em função da quantidade e detalhamento de informações existentes sobre a área estudada. Podem ser classificadas como:

-Potencialmente contaminadas (APs): onde foram ou estão sendo desenvolvidas atividades potencialmente contaminadoras;

-Suspeitas de contaminação: aquelas que, durante a avaliação preliminar, foram observadas constatações que induzem a suspeitar de contaminação no solo ou água subterrânea;

-Área contaminada: onde há comprovadamente contaminação confirmada por análises.

As informações obtidas sobre a área contaminada devem constar no cadastro de áreas contaminadas do município, o qual constitui elemento central do gerenciamento de ACs.

Essas informações podem ser utilizadas no controle e planejamento ambiental ou fornecidas para outras instituições públicas ou privadas. 0 gerenciamento deve ser executado pelo órgão ambiental responsável no âmbito municipal ou estadual que se responsabilizará pela etapa de identificação e pela fiscalização da etapa de recuperação que caberá ao responsável, de acordo com o princípio do "poluidor pagador".

A origem das áreas contaminadas pode estar relacionada ao desconhecimento, em épocas passadas, de procedimentos seguros para o manejo e disposição de substâncias perigosas (lixos e resíduos), ao desrespeito a procedimentos seguros e à ocorrência de acidentes ou vazamentos durante o desenvolvimento dos processos produtivos, de transporte ou de armazenamento de matérias primas e produtos.

A fase de estudo sobre processos industriais, armazenamento e manipulação de produtos químicos, resíduos gerados, destino dos efluentes, tratamento e despejo no meio ambiente, interferência ambiental e social da poluição gerada, bem como possíveis vestígios de contaminação na área restringindo novas ocupações são parte da "Fase I" do estudo sobre contaminação de uma área de acordo com Russ (2000). Segundo o Manual de ACs (CETESB e GTZ, 1999) o levantamento de informações a respeito de uma área faz parte do processo de identificação da ACs. O solo e a água subterrânea são meios prioritários a ser considerados no gerenciamento de ACs, pois, além de ser bens a proteger de extrema importância, normalmente são as principais vias de propagação de contaminantes para outros bens a proteger.

Dessa forma, na definição dos objetivos do gerenciamento de ACs em uma determinada região de interesse, a proteção da qualidade do solo e das águas subterrâneas deve ser prioritária (CETESB, 2003). Na definição da região de interesse, deve ser determinado o seu limite e o posicionamento dos bens a proteger no seu interior. 
Pode ser feito pela utilização de mapas normalmente em escala regional.

A avaliação preliminar consiste na elaboração de um diagnóstico inicial de APs, realizada na etapa anterior com o levantamento das informações existentes, dados históricos e de trabalhos de campo visando caracterização da AP. Devem ser documentados evidências ou fatos que levem a suspeita de contaminação, possibilitando classificação como AS, AP ou AC, ou ainda, exclusão do cadastro. As medidas emergenciais podem ser tomadas também nesta etapa. Segundo o Manual de Gerenciamento de ACs (CETESB e GTZ, 1999) várias fontes podem ser consultadas na obtenção dessas informações, como, por exemplo, processos e relatórios do órgão de controle ambiental, arquivos existentes nas prefeituras, documentos existentes no próprio empreendimento ou com seu proprietário, mapas e fotografias aéreas multitemporais, entre outros. Aobtenção de dados através de inspeção de reconhecimento da área é feita por meio de observações em campo e por entrevistas com pessoas do local, possibilitando responder algumas das questões da Ficha Cadastral de Áreas Contaminadas, como, por exemplo, as substâncias utilizadas, o estado geral das instalações, o uso do solo na área e em seus arredores e a existência de bens a proteger. Os dados obtidos devem ser interpretados, visando formular hipóteses sobre as características da fonte de contaminação, as prováveis vias de transporte dos contaminantes (meios onde pode se propagar), a distribuição espacial da contaminação e os prováveis receptores ou bens a proteger atingidos.

Dessa forma, estabelece-se um modelo conceitual inicial da área, que poderá ser utilizado como base para o planejamento das etapas de investigação confirmatória e detalhada.

A etapa da investigação confirmatória finaliza o processo afirmando se há contaminação. As ASs são avaliadas por métodos diretos e indiretos podendo classificar a área como AC. Os resultados obtidos na etapa de investigação confirmatória são importantes para subsidiar as ações do órgão gerenciador ou órgão de controle ambiental na definição do responsável pela contaminação e dos projetos a serem implantados. A análise de ACs é realizada com ensaios laboratoriais com amostras de solo e água subterrânea. Para locar esses pontos e definir a profundidade de investigação, toma-se como base o conhecimento adquirido sobre a área na etapa anterior (avaliação preliminar), onde foi definido o modelo conceitual inicial da área.

Áreas incluídas no cadastro como ACs devem ser incluídas no processo de recuperação, enquanto as APs deverão permanecer no cadastro aguardado novas priorizações. 0 processo de investigação detalhada é o primeiro na etapa de recuperação. A metodologia utilizada para a etapa de investigação detalhada é semelhante à utilizada para a etapa de investigação confirmatória, mas os objetivos são diferentes. $\mathrm{Na}$ etapa de investigação confirmatória o objetivo principal é confirmar a presença de contaminação, na etapa de investigação detalhada o objetivo principal é quantificar a contaminação, isto é, avaliar detalhadamente as características das fontes e dos meios afetados, determinando-se as dimensões afetadas, os tipos e concentrações de contaminantes presentes. Devem ser definidas as características da pluma de contaminação, seus limites e taxa de propagação.

A avaliação quantifica os riscos gerados pela contaminação aos bens a proteger como a saúde da população e os ecossistemas. Essa quantificação é baseada em princípios de toxicologia, química e no conhecimento sobre o comportamento e transporte dos contaminantes. Esta avaliação determinará a necessidade de remediação e qual será adotada para novo uso da área. Nesta etapa são levantadas as técnicas e planos, ensaios de projetos pilotos, realização de modelagem matemática, interpretação de resultados e definição da técnica. 0 projeto de remediação deve ser utilizado como a base técnica para o órgão gerenciador ou órgão de controle ambiental avaliar a possibilidade de autorizar ou não a implantação.

A remediação de ACs consiste na implementação de medidas que resultem no saneamento da área contaminada e/ou na contenção e isolamento dos contaminantes, de modo a atingir os objetivos. 0 projeto deve ser continuamente avaliado de modo a verificar sua real eficiência. O encerramento dessa etapa se dará, após anuência do órgão de controle ambiental, quando os objetivos definidos forem atingidos. A partir dos resultados obtidos nesse monitoramento, será possível realizar uma nova etapa de classificação, na qual a área poderá ser classificada como AP, caso a contaminação tenha sido removida e continue existindo uma atividade potencialmente contaminadora na área. Uma área poderá permanecer como AC quando continuar existindo contaminação na área, mesmo que os riscos aos bens a proteger tenham sido eliminados ou minimizados pela aplicação das técnicas de remediação. Uma área poderá ser excluída do Cadastro de ACs quando a contaminação for removida e não existir mais atividades potencialmente contaminadoras.

A próxima etapa é a realização do Cadastro de áreas contaminadas composto pelo cadastro físico: fichas cadastrais e de pontuação, mapas contendo a localização das áreas e bens a proteger, relatórios emitidos durante o desenvolvimento das etapas do gerenciamento de ACs, além de outras informações referentes à área.

A Ficha Cadastral de ACs é o elemento central para coleta e organização de dados e, conseqüentemente, para alimentação do Cadastro de ACs. As informações obtidas através da ficha podem ser agrupadas por meio 
de dados relativos à natureza e características da fonte de contaminação; dados relativos à existência e características dos bens a proteger; dados indicativos da forma de propagação dos contaminantes; informações sobre as ações adotadas em relação à avaliação e remediação da área. De acordo com base nas informações registradas na ficha cadastral, as áreas são classificadas em AP, AS ou AC, dependendo da etapa do gerenciamento que se tenha atingido. Este cadastro deve sempre ser atualizado, subsidiando:

-Administração pelo órgão gerenciador ou
responsável;

-Diagnósticos e análises regionais;

-Adoção de ações de controle ambiental;

-Planejamento de ocupação;

-Apresentação de dados referentes às áreas.

\section{Reabilitação de brownfields urbanos}

A reabilitação de brownfields tem como objetivo limpeza ambiental, a recuperação dos espaços abandonados e o aproveitamento, quando possível, das estruturas locais. Estes são projetos onerosos que necessitam de parcerias de diversas entidades. Os governos e agências engajadas, portanto, devem prover os recursos humanos e financeiros, assim como também a ajuda técnica multidisciplinar. 0 governo local deve incluir o planejamento, desenvolvimento econômico, serviços ambientais, programas de comunidade, avaliação de risco e da saúde pública.

Geralmente, além da contaminação, as comunidades próximas aos brownfields enfrentam freqüentemente problemas como desemprego, moradias precárias e infraestruturas urbanas decadentes. Desse modo, cada uma destas perspectivas deve ser analisada e sanada, fazendo com que a requalificação do bairro adquira um caráter mais social. Os governos devem encorajar a refuncionalização, concedendo incentivos fiscais e eliminando os entraves legais e administrativos, pois a iniciativa governamental nestes programas garante maiores chances na atração de investidores. As decisões dos governos precisam estar baseadas em uma justa apreciação do bem público, e serem transparentes na sua aplicação. No que tange à parte ambiental, o setor público deveria fazer da proteção ambiental uma prioridade social e legal.

Segundo VASQUES (2005, p.55) a relação de uma comunidade com uma indústria em funcionamento é diferente da relação que se estabelece quando a mesma encontra-se abandonada. Enquanto tem um uso produtivo, uma indústria pode ser relevante, segundo a opinião pública, em decorrência dos empregos que oferece, do desenvolvimento econômico que proporciona, dos impostos que arrecada para o município, etc. Ela também pode ser um entrave em decorrência dos problemas de poluição, ruído e degradação ambiental gerados. Quando uma indústria fecha, seja por motivos econômicos (crise ou declínio industrial), de obsolescência (não acompanhamento das novas tecnologias para produção), mau funcionamento dos mercados (custos elevados da restauração e aquisição de terrenos, comportamento especulativo dos proprietários) etc., a comunidade deixa de receber os benefícios. 0 fechamento, então, gera desemprego, terrenos e edifícios que se degradam com o tempo, o espaço ocioso se converte em habitação de mendigos e, por fim, a economia local fica estagnada.

Nestas condições, aquele espaço antes produtivo tornase espaço de medo, de rejeição, de marginalidade, convertendo-se em uma paisagem urbana cujos elementos a população não deseja ver pela frente. Os autores VANT e Thomas (1991, p.129) analisam os eixos prioritários da política urbana de municípios franceses e colocam como objetivo triplo: frear a expansão periférica, parar a especulação imobiliária e promover na população residente a melhoria da qualidade de vida, entendendo que este conceito engloba a melhoria de equipamentos sócio-culturais. Nesta perspectiva, reinvestiria-se em comunidades já existentes e incentivaria-se que as próprias se organizassem para decidir os novos usos para as velhas fábricas abandonadas. As potencialidades e restrições que um local apresenta são bem conhecidas pela população que nele habita. As necessidades de um bairro podem ser supridas de uma melhor forma quando seus moradores se organizam e decidem em conjunto de quais espaços carecem: áreas verdes, recreação, creches, escola, e outros.

Preparar a comunidade através de treinamentos, para que esta adquira o conhecimento técnico adequado para auxiliar nos projetos de limpeza da área, é uma forma de investimento na educação da população e no despertar da consciência ambiental. Além disso, os custos de intervenção são minimizados porque a comunidade local trabalha de forma voluntária, uma vez que será recompensada com as novas atividades e a valorização do meio onde vivem.

A criação de grupos de limpeza voluntários vem sendo uma prática comum em comunidades norteamericanas afetadas pelo processo de industrialização - desindustrialização. O "Voluntary Clean up Program" existe em várias cidades norteamericanas, encorajando a limpeza voluntária dos brownfields para a proteção da saúde pública e do meio ambiente, além de estimular a economia local via novas atividades. A queda de barreiras entre o poder político local e a sociedade civil não constitui tarefa simples, em razão das raízes 
culturais autoritárias instauradas em nossa história. Porém, esta iniciativa traz resultados importantes para a definição de metas e prioridades a serem atendidas. A sociedade, ao sentir o envolvimento e a responsabilidade a ela delegada, passa a exercer a sua cidadania de forma cooperativa, organizando em parceria com o poder local discussões dos problemas e busca de soluções, pactuando um acordo de mútuo auxílio. Os benefícios sociais que podem ser esperados após a reabilitação de brownfields, como por exemplo, a criação de empregos, a revalorização do entorno, e os novos usos ajustados com as necessidades do bairro, devem servir de estímulo para que a comunidade vizinha se organize e participe da reconversão destes espaços.

\section{Conclusão}

O reconhecimento da contaminação, a avaliação dos seus riscos ao homem e ao meio ambiente e, finalmente, o gerenciamento ambiental através da adoção de métodos para eliminar ou reduzir os impactos ambientais como a contaminação, são procedimentos que devem ser tomados a fim de sanar o problema da poluição de solos e águas. Quanto mais cedo forem tomadas as devidas providências, maiores as chances de recuperação dos terrenos. Neste sentido, a legislação ambiental exerce papel primordial na legalização das ações voltadas para a recuperação destas áreas, e posterior uso destes espaços pela população.

O ideal, ainda muito longe da realidade, é que a desativação de empreendimentos seja feita calculando o ciclo de vida das atividades; mesmo que não se saiba quando será seu fim, é possível estimar a vida útil dos mesmos e antecipar a obsolescência. Quando uma instalação não serve mais ao seu propósito original, em termos funcionais, ela se torna obsoleta. É necessário frisar que nem todos os brownfields apresentam contaminação ou qualquer tipo de passivo ambiental, já que muitas atividades econômicas foram exercidas sem deixar danos deste tipo ao meio ambiente físico e social. Esta discussão levantada acerca dos passivos serve, portanto, para os casos de brownfields afetados pelo problema de resíduos e agentes contaminadores em atividades poluidoras passadas. A reciclagem do solo urbano representa a oportunidade de valorizar um patrimônio e recuperar um recurso - o solo.

\section{Referências bibliográficas}

Bшє, P. (1999) - “La responsabilité des propriétaires de sites contaminés, ou le triomphe des apparences". Revue de Geographie de Lyon, vol.74, n³, pp.225-231.

CETESB, GTZ (1999) - Legislação Brasileira. Edição atualizada. 1999. Manual de Gerenciamento de áreas contaminadas.

CETESB (2003) - Anteprojeto de Lei sobre proteção da qualidade do solo e gerenciamento de áreas contaminadas. São Paulo. Disponível em www. cetesb.sp.gov.br/Noticias/003/10/minuta_ final_consema.pdf. Acesso em: 27 jul. 2006.

Cunha, R. C. A. (1997) - "Avaliação de risco em áreas contaminadas por fontes industriais desativadas - estudo de caso". Tese (Doutorado) - Instituto de Geociências, Universidade de São Paulo, São Paulo.

GRIMSKI, D. (2004) - "Revitalização de áreas degradadas e contaminadas na Alemanha e Europa". In: Rodrigues, D. Remediação e Revitalização de Áreas Contaminadas. São Paulo, Signus, p. 3-15.

Guelton, S. (1999) - "Les enjeux financiers de la dépollution des anciens sites industriels". Revue de Geographie de Lyon, vol.74, n³, pp.233-240.

Lage, H. (2003) - "Passivo Ambiental. Meio Ambiente Industrial", Ano VII, Edição 41, n 40 , Janeiro/ Fevereiro de 2003, p.32-34.

Russ, T.H. (2000) - "Redeveloping Brownfields". New York, Mcgraw-Hill Professi.

SAnchez, L.E. (2001) - "Desengenharia - O Passivo Ambiental na Desativação de Empreendimentos Industriais". São Paulo, Edusp/Fapesp.

Santos, A. S. R. (2003) - "Princípios do Direito Ambiental. Meio Ambiente Industrial", Ano VII, Edição 41, $n^{\circ} 40$, Janeiro/Fevereiro de 2003, p.52-54.

VANT, A.; Thomas, E. (1991) - "Entre le local et le global, Les pratiques stéphanoises de requalification socio-spatiales". Revue de Géographie de Lyon, vol. 66, $\mathrm{n}^{\circ} 2$, p. 122-135.

VASQues, A R. (2005) - "Refuncionalização de brownfields. Estudo de caso na zona leste de São Paulo-SP". Dissertação (Mestrado em Geografia) - Instituto de Geociências e Ciências Exatas, Universidade Estadual Paulista, Rio Claro.

Volpe, L. L. (2006) - "Estudo sobre contaminação de solo em áreas de passivos sócio-ambientais industriais têxteis: o exemplo de Americana SP". Relatório (Especialização em Geografia) Instituto de Geociências e Ciências. 